\title{
Mesoporous Alumina Microfibers In Situ Transformation from AACH Fibers and the Adsorption Performance
}

\author{
Xiaoqin Shi, Chen Yang, Liang Zhang, Zhongding Lu, Yun Zhu, Dayu Tang, \\ Chong Cui, and Haibo Zeng \\ School of Materials Science and Engineering, University of Science and Technology, Nanjing 210094, China \\ Correspondence should be addressed to Xiaoqin Shi; sxq@mail.njust.edu.cn and Chong Cui; cuichong@njust.edu.cn
}

Received 11 November 2013; Accepted 6 December 2013; Published 29 January 2014

Academic Editor: Hui Xia

Copyright (c) 2014 Xiaoqin Shi et al. This is an open access article distributed under the Creative Commons Attribution License, which permits unrestricted use, distribution, and reproduction in any medium, provided the original work is properly cited.

\begin{abstract}
Well-dispersed mesoporous $\gamma$-alumina microfibers with high surface were prepared by thermal decomposition of the ammonium aluminum carbonate hydroxide $(\mathrm{AACH})$ precursors. The as-synthesized alumina retained the morphology of its precursor and exhibited memory effect. The structural, morphological, porous, and adsorptive properties of the samples were investigated by XRD, FTIR, TGA-DSC, SEM, TEM, and UV-vis spectroscopy. The prepared $\gamma$-alumina microfibers exhibited excellent ability to remove organic pollutants from waste water because of their mesoporous structures. The $\gamma$-alumina in situ converted from AACH synthesized without surfactant exhibited adsorption ability for Congo red as good as that synthesized with PEG2000 and better than PEG20000 that provided a facile method without surfactant to synthesize $\gamma$-alumina with excellent adsorption performance.
\end{abstract}

\section{Introduction}

In recent years, considerable attention has been paid to the environmental pollution problems. Materials with mesoporous structure are expected useful in the water treatments. Alumina are widely used as catalyst supports, adsorbents, ceramics, and abrasives, [1]. Alumina have been prepared in different morphologies including nanowhiskers [2], nanoflakes [3], nanowires [4], nanofibers [5], nanorods, and nanotubes [6]. They may be categorized as one- and twodimensional nanostructures. A great deal of recent effort has been placed on the synthesis of mesoporous alumina with a high specific surface area and large pore volume using various templates, including surfactants, [7-10] carboxylic acids, [11] and single organic molecules (e.g., glucose [12], tetraethyl glycol $[13,14]$, and tartaric acid [15]). The introduction of hydrothermal process has provided a relatively simple and powerful method for synthesis of 1D mesoporous nanostructures [16].

Recently, many reports studied the preparation of the morphology-controlled alumina materials via a novel AACH precursor due to its special crystal structure $[1,16]$, which are benefits to the preparation of the morphology-controlled and mesopores-remained $\mathrm{Al}_{2} \mathrm{O}_{3}$ products. Herein, we present a facile hydrothermal and thermal decomposition route to synthesis mesoporous $\gamma-\mathrm{Al}_{2} \mathrm{O}_{3}$ fibers with uniform diameters without or with different surfactant. The possible formation process and subsequently surfactant-induced growth mechanism is proposed. Finally, both of the as-obtained alumina fibers were used to adsorb Congo red from water solution.

\section{Experimental}

2.1. Preparation of Samples. In a typical synthesis of AACH precursors, $0.1 \mathrm{mmol}$ of polyglycol (PEG)-20000 or polyglycol (PEG)-2000 was dissolved in $8 \mathrm{~mL}$ deionized water to form a transparent solution, to which $15.0 \mathrm{~g}$ of $\mathrm{Al}\left(\mathrm{NO}_{3}\right)_{3} \cdot 9 \mathrm{H}_{2} \mathrm{O}$ (Merck, 98.5\%) was added under vigorous stirring. Then, urea $(0.45 \mathrm{~mol})$ was added. The final mixture was then transferred into Teflon-lined autoclave, which was then sealed and placed in an electric oven at $140^{\circ} \mathrm{C}$. After $24 \mathrm{~h}$, the autoclave was cooled naturally to room temperature. The product was collected by centrifugation then washed with distilled water and absolute ethanol for several times to remove the impurities and finally dried at $80^{\circ} \mathrm{C}$.

The precursors synthesized above were calcined at $900^{\circ} \mathrm{C}$ for $2 \mathrm{~h}$ to obtain alumina. 


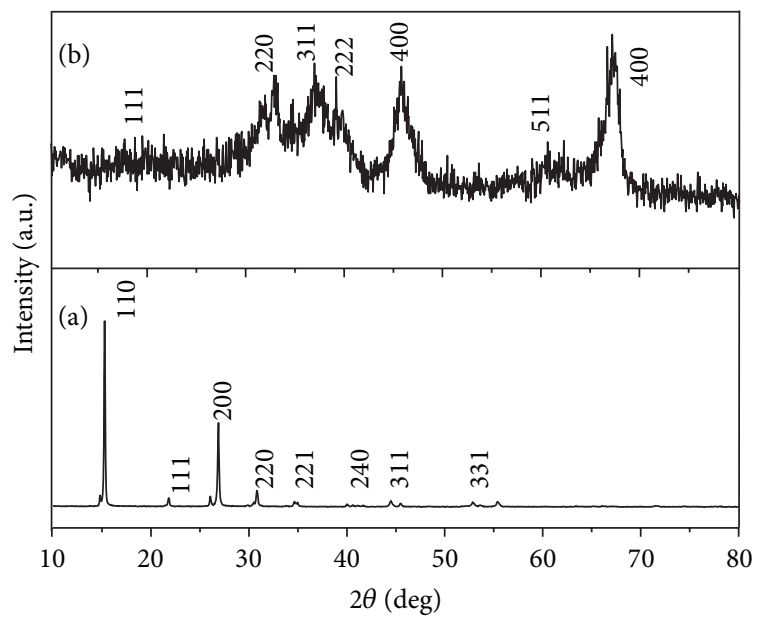

FIGURE 1: XRD patterns of AACH samples prepared at $140^{\circ} \mathrm{C}$ for $24 \mathrm{~h}$ (a), together with its respective conversion to $\gamma-\mathrm{Al}_{2} \mathrm{O}_{3}$ sample calcined at $900^{\circ} \mathrm{C}$ for $2 \mathrm{~h}(\mathrm{~b})$.

2.2. Characterization. X-ray diffraction (XRD) patterns were recorded on a powder X-ray diffractometer (D8 advance, Bruker, Germany) with $\mathrm{Cu}$ Ka radiation. Scanning electron microscopy (SEM) images were obtained using a fieldemission scanning electron microscope (LEO 1550, ZEISS, Germany) operated at $5 \mathrm{KV}$ and a transmission electron microscope (JSM-6380LV, JEOL, Japan) operated at $200 \mathrm{KV}$. The nitrogen adsorption isotherms and special surface areas were obtained using a Quantachrome Nova2000e surface area and pore size analyzer. The sample was degassed at $250^{\circ} \mathrm{C}$ under a vacuum for $5 \mathrm{~h}$. The special surface areas were calculated using the Brunauer-Emmett-Teller (BET) model from a linear part of BET plot $\left(P / P_{0}=0.10-0.30\right)$. Average pore diameters were calculated using the BarrettJoyner-Halenda (BJH) method from the desorption branch of isotherm. Chemical bonding information on product was recorded with a Nicolet IS-10 FTIR spectrometer (Thermo Fisher Scientific, USA) using the potassium bromide (KBr) pellet technique with a resolution of $4 \mathrm{~cm}^{-1}$ between 400 and $4000 \mathrm{~cm}^{-1}$. The UV-vis absorption spectrum of the products was recorded using a UV-2045 UV-visible spectrometer. The thermal behavior of the products was characterized with a STA 449C TGA-DSC. In each experiment, about $10 \mathrm{mg}$ of the sample was heated at a rate of $10^{\circ} \mathrm{C} / \mathrm{min}$ from 30 to $1300^{\circ} \mathrm{C}$.

2.3. Waste Water Treatment. Both of the alumina fibers were used to adsorb Congo red from water solution. $5 \mathrm{mg}$ as-obtained particles were, respectively, added to $10 \mathrm{~mL}$ Congo red $\left(\mathrm{C}_{20} \mathrm{H}_{19} \mathrm{~N}_{3}\right)$ solution $(75 \mathrm{mg} / \mathrm{L})$ under stirring continuously at room temperature. Analytical samples were taken from the suspension after various adsorption times and centrifuged to remove the particles. UV-vis absorption spectra were recorded at different intervals to monitor the process.

\section{Results and Discussions}

As shown in Figure 1, the as-synthesized sample at $140^{\circ} \mathrm{C}$ for $24 \mathrm{~h}$ (curve (a)) was identified as the hexagonal ammonium

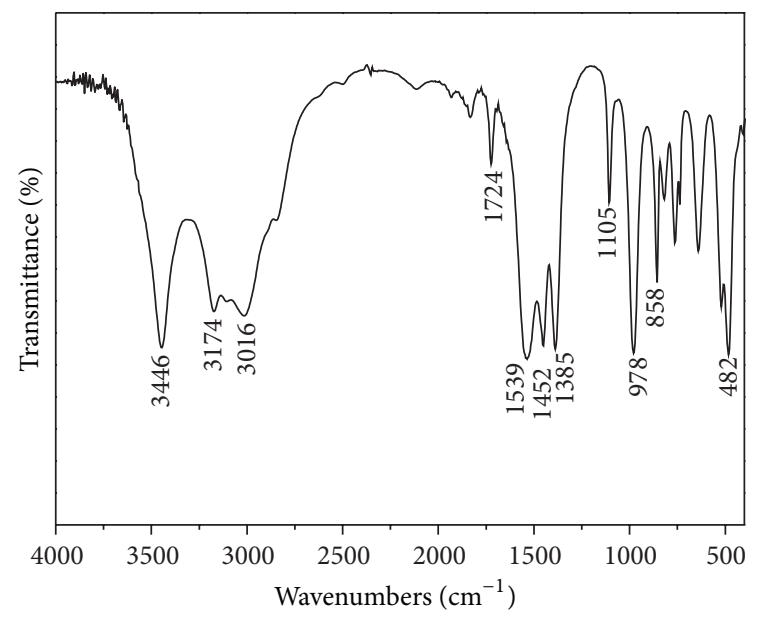

Figure 2: FTIR spectrum of the synthesized AACH.

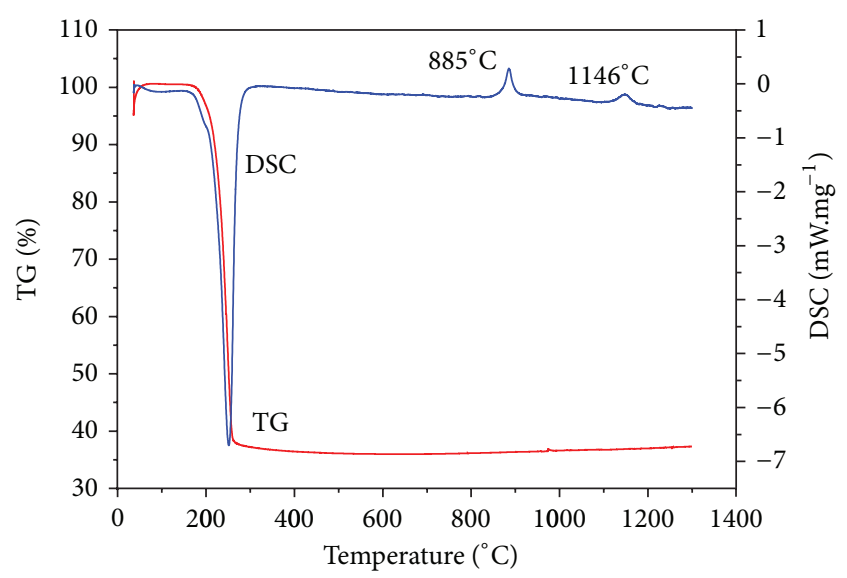

FIgURE 3: TGA-DSC curves of AACH precursor.

aluminum carbonate hydroxide (denoted as AACH) (JCPDS card no. 29-0106) by X-ray diffractometer. The high intensity of the XRD peaks of the as-synthesized samples indicated that the $\mathrm{AACH}$ phase synthesized in this work is highly crystalline. The respective sample calcined at $900^{\circ} \mathrm{C}$ for $2 \mathrm{~h}$ (curve (b)) can be identified as cubic $\gamma-\mathrm{Al}_{2} \mathrm{O}_{3}$ (JCPDS card no. 10-0425). The low intensity of the XRD peaks indicates the alumina products calcined at this temperature that have a low crystallinity.

The FTIR spectrum of the as-synthesized AACH was shown in Figure 2. The band at $1452-1539 \mathrm{~cm}^{-1}$ was attributed to the asymmetrical stretching vibration of $\mathrm{CO}_{3}$ bonds. Peaks at 3446 and $978 \mathrm{~cm}^{-1}$ are due to stretching and bending of hydroxyl group in AACH. Bands at $3016-3173 \mathrm{~cm}^{-1}$ and $1385 \mathrm{~cm}^{-1}$ are due to symmetric and asymmetric stretching vibration of $\mathrm{NH}_{4}$. The bands at $468,611,733$, and $848 \mathrm{~cm}^{-1}$ are ascribed to vibration modes of $\mathrm{Al}-\mathrm{O}$, while strong band at $1105 \mathrm{~cm}^{-1}$ is due to $\mathrm{Al}-\mathrm{O}-\mathrm{Al}$ symmetric vibrations. The absorption bands at $858 \mathrm{~cm}^{-1}$ and $482 \mathrm{~cm}^{-1}$ belong to C-O$\mathrm{C}$ and $-\mathrm{CH}_{2}-$ vibration, which originates from surfactant of PEG, and the result suggests that some PEG molecules are absorbed onto the surface of AACH particles.

The TGA-DSC curves of the AACH are shown in Figure 3. The TGA curve shows that the sample has two major 


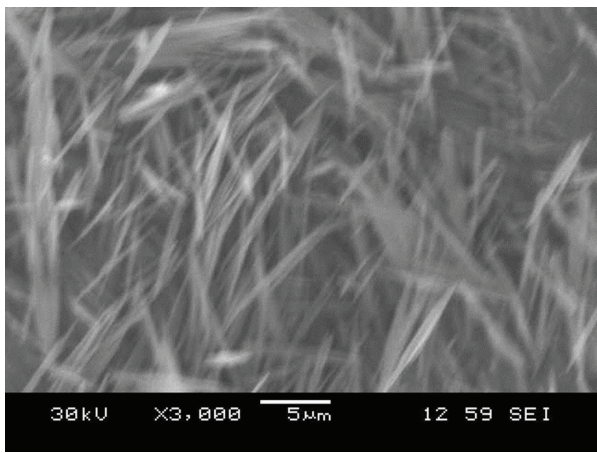

(a)

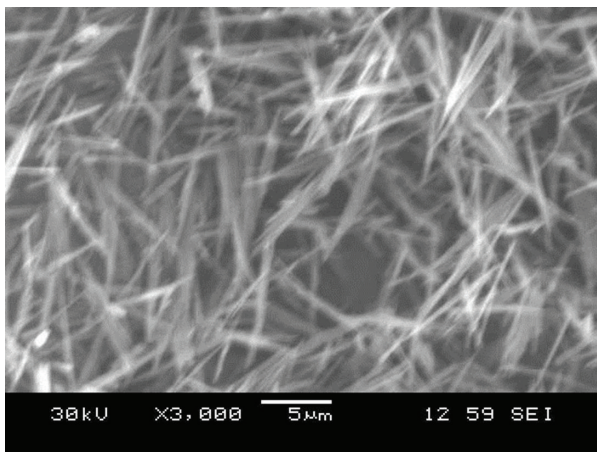

(c)

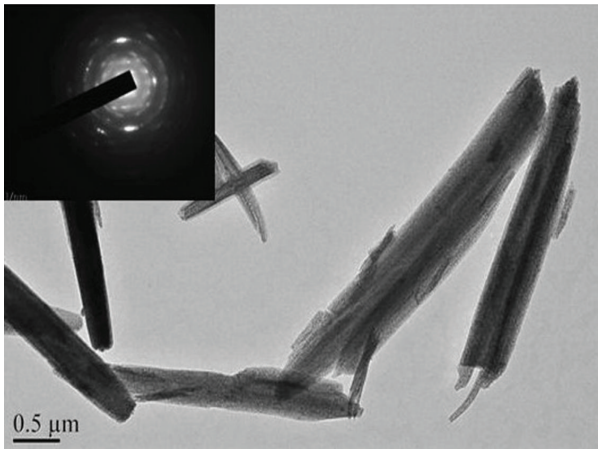

(e)

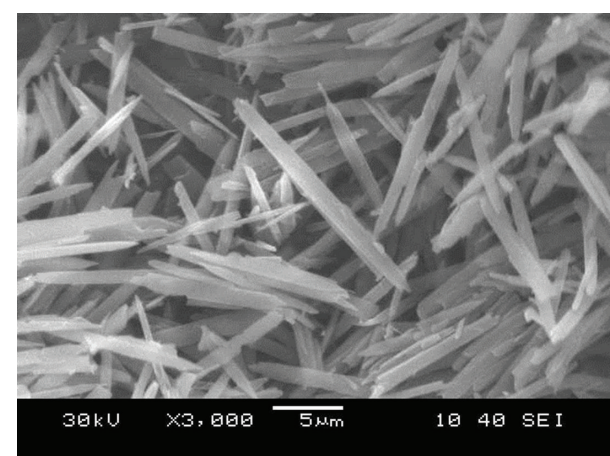

(b)

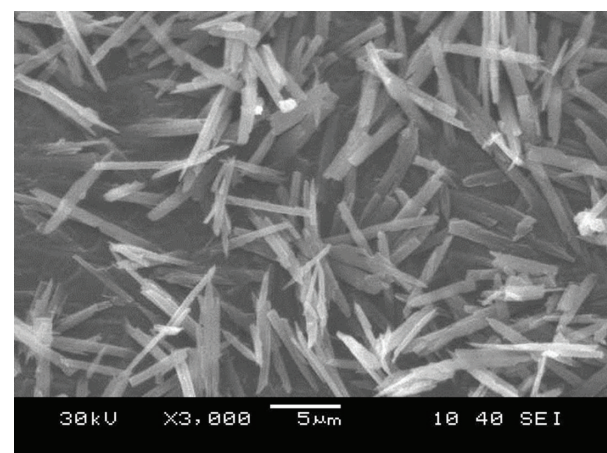

(d)

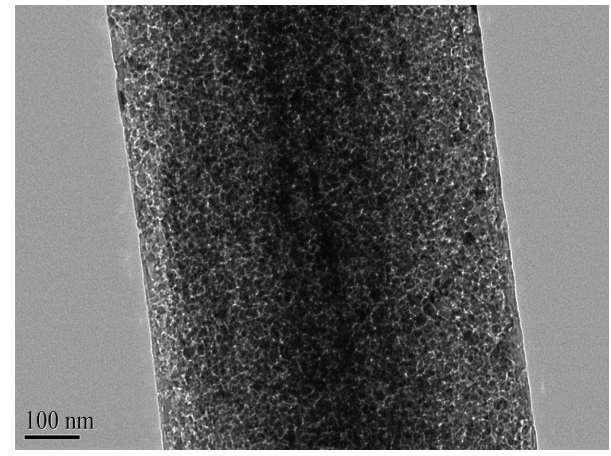

(f)

FIGURE 4: SEM images of AACH microfibers prepared with no surfactant: (a) PEG20000, (b) PEG2000, (c) SEM, and (e) TEM ((c), (d)) images of $\gamma-\mathrm{Al}_{2} \mathrm{O}_{3}$ microfibers prepared by calcination at $900^{\circ} \mathrm{C}$ for $2 \mathrm{~h}$.

weight losses. The first weight loss below $208^{\circ} \mathrm{C}$ is due to the desorption of physically adsorbed water. The second weight loss in the temperature range of $208-251^{\circ} \mathrm{C}$, corresponding to the large exothermic peak at $251^{\circ} \mathrm{C}$ of the DSC curve, is associated with the decomposition of PEG20000, together with the conversion of $\mathrm{AACH}$ to amorphous $\mathrm{Al}_{3} \mathrm{O}_{2}$ by release of $\mathrm{H}_{2} \mathrm{O}, \mathrm{NH}_{3}$, and $\mathrm{CO}_{2}$. With the consideration of the weight loss due to absorbed water and PEG, the total weight loss is about $63.8 \%$ which is in good agreement with theoretical calculations $63.3 \%$ according to the reaction: $2 \mathrm{NH}_{4} \mathrm{Al}(\mathrm{OH})_{2} \mathrm{CO}_{3} \rightarrow \mathrm{Al}_{2} \mathrm{O}_{3}+2 \mathrm{NH}_{3}$ (12.23\% wt loss) $+2 \mathrm{CO}_{2}$ (31.65\% wt loss) $+3 \mathrm{H}_{2} \mathrm{O}$ (19.42\% wt loss). The two Endothermic peaks at $885^{\circ} \mathrm{C}$ and $1146^{\circ} \mathrm{C}$ on DSC curve without weight loss on TG curve should be attributed to the phase transformation into $\gamma-\mathrm{Al}_{2} \mathrm{O}_{3}$ and $\alpha-\mathrm{Al}_{2} \mathrm{O}_{3}$, respectively [17].
As shown in SEM images of AACH prepared with no surfactant (Figure 4(a)), PEG20000 (Figure 4(b)), and PEG2000 (Figure $4(\mathrm{c})$ ), the sample is composed of microfibers with uniform size. The length of the fibers is about $10 \mu \mathrm{m}$, and the diameter of the fibers is about $500 \mathrm{~nm}$ for Figures 4(a) and $4(\mathrm{c})$, and $1 \mu \mathrm{m}$ for Figure $4(\mathrm{~b})$. The formation of $\mathrm{AACH}$ follows the following equation:

$$
\begin{aligned}
& \mathrm{Al}\left(\mathrm{NO}_{3}\right)_{3}+3 \mathrm{CO}\left(\mathrm{NH}_{2}\right)_{2}+8 \mathrm{H}_{2} \mathrm{O} \\
& \longrightarrow \mathrm{NH}_{4}\left[\mathrm{Al}(\mathrm{OOH}) \mathrm{HCO}_{3}\right] \downarrow+3 \mathrm{NH}_{4} \mathrm{NO}_{3}+2 \mathrm{NH}_{4} \mathrm{HCO}_{3} .
\end{aligned}
$$

The formation of the alumina nanofibers could be interpreted using a surfactant-induced fiber formation (SIFF) mechanism brought forward by Zhu et al. [18], that is, AACH nanocrystals adsorbed on the PEG micelles via hydrogen 


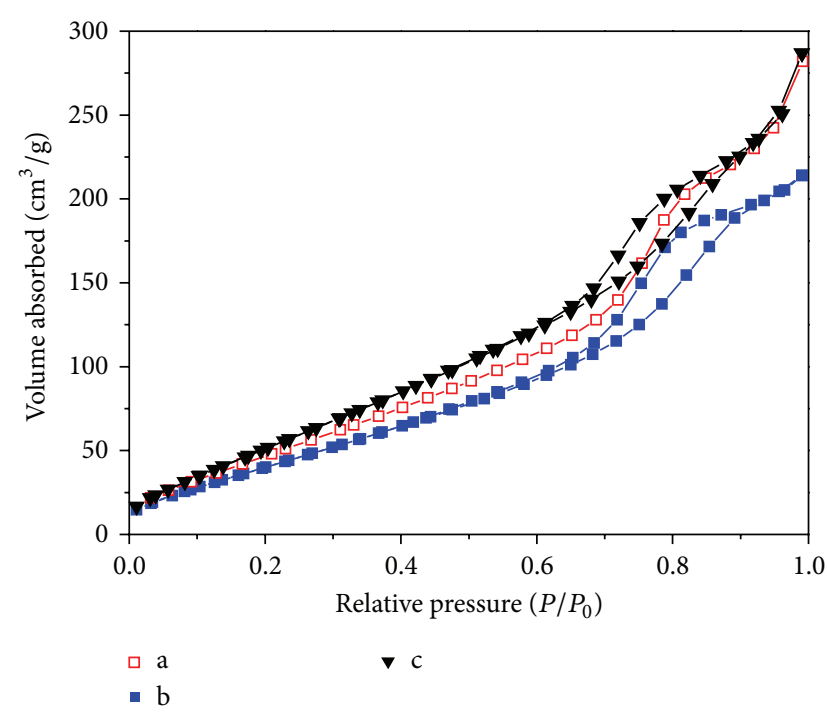

(A)

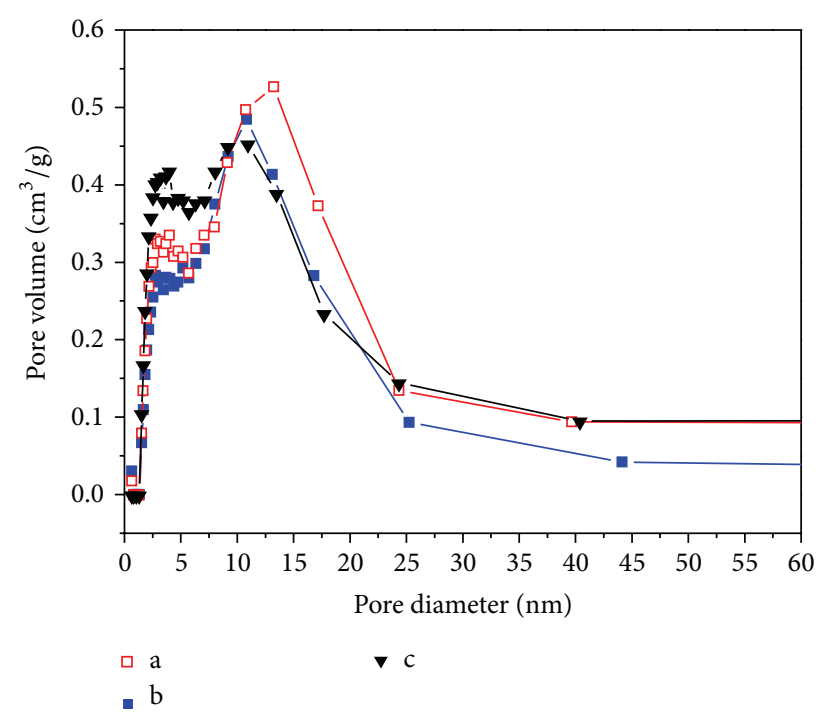

(B)

FIGURE 5: (A) $\mathrm{N}_{2}$ absorption and desorption isotherms and (B) pore-size distributions of $\gamma$ - $\mathrm{Al}_{2} \mathrm{O}_{3}$ transformed from AACH prepared with surfactant of (a) no surfactant, (b) PEG20000, and (c) PEG2000, respectively.

bonding of the oxide groups of PEG with the $\mathrm{OH}$ groups of AACH. The hydrogen bonding reduces the free energy of the AACH crystallites, which allows the AACH crystallites to grow into $\mathrm{AACH} / \mathrm{PEG}$ nanorods along the direction of the axis of the rod-shaped copolymer micelles. As shown in Figures 4(a)-4(c), AACH microfibers prepared with no surfactant have the same morphology with the samples prepared with PEG20000 and PEG2000. That is the result of preferred growth of AACH along the crystallographic caxis. The diameter of the fibers derived from $\mathrm{AACH}$ prepared with PEG20000 was larger than the others that may be due to the larger rod-shaped micelles of PEG20000 formed from the longer carbochain.

SEM and TEM images of the $\gamma-\mathrm{Al}_{2} \mathrm{O}_{3}$ microfibers prepared by the thermal decomposition of the AACH fibers shown in Figure $4(\mathrm{~b})$ at $900^{\circ} \mathrm{C}$ for $2 \mathrm{~h}$ were shown in Figures 4(d)-4(f). As shown in Figure 4(d), the alumina fibers are relatively small in diameter than its $\mathrm{AACH}$ precursors, and the microfibers were comprised of worm-like mesopores with the pore size about $10 \mathrm{~nm}$ (shown in Figure 4(f)) that is probably induced by shrinkage during calcination accompanied by release of $\mathrm{H}_{2} \mathrm{O}$ and decomposition of PEG and AACH precursor. The corresponding selected area electron diffraction pattern (Figure 4(e) inset) indicated the typical diffraction rings of the polycrystalline phase.

The $\mathrm{N}_{2}$ adsorption-desorption isotherm of the $\gamma-\mathrm{Al}_{2} \mathrm{O}_{3}$ microfibers calcined at $900^{\circ} \mathrm{C}$ for $2 \mathrm{~h}$ was presented in Figure 5. All of the samples exhibited type IV isotherm with hysteresis of type $\mathrm{H} 1$ in the relative pressure range of $0.6-1.0$, indicating the presence of the inhomogeneous mesopores. The specific surface areas were $212.43 \mathrm{~m}^{2} / \mathrm{g}, 182.26 \mathrm{~m}^{2} / \mathrm{g}$, and $235.84 \mathrm{~m}^{2} / \mathrm{g}$, respectively, by the BET method for $\gamma$ $\mathrm{Al}_{2} \mathrm{O}_{3}$ transformed from $\mathrm{AACH}$ prepared with surfactant of (a) no surfactant, (b) PEG20000, and (c) PEG2000. The corresponding pore size distribution curve (Figure 6) of the three samples all displayed pore size distribution from 3 to $25 \mathrm{~nm}$, centered at $12 \mathrm{~nm}((\mathrm{~b})$ and (c)) and $15 \mathrm{~nm}$ (a), which is close to the result from the TEM images. The calculated pore volume by the $\mathrm{BJH}$ method is $0.4899 \mathrm{~cm}^{3} / \mathrm{g}, 0.3782 \mathrm{~cm}^{3} / \mathrm{g}$, and $0.5089 \mathrm{~cm}^{3} / \mathrm{g}$ for samples (a), (b), and (c), respectively. By comparison, $c>a>b$ for both of the specific surface area and pore volume.

The UV-vis spectra of Congo red solutions in the presence of $\gamma-\mathrm{Al}_{2} \mathrm{O}_{3}$ transformed from AACH prepared with surfactant of PEG2000 were taken over time at room temperature (Figure 6(A)). Where Congo red is a common azo-dye in the textile industry and was chosen as a model organic waste. When $5 \mathrm{mg}$ of $\gamma-\mathrm{Al}_{2} \mathrm{O}_{3}$ was added into $10.0 \mathrm{~mL}$ Congo red solution $(75 \mathrm{mg} / \mathrm{L})$, the absorption of Congo red was decreased to $1.8 \%$ within 20 mins and Congo red was removed almost completely after 30 mins. The removal of Congo red can be attributed to the electrostatic attraction between the surface of mesoporous alumina microfibers and Congo red molecules [19]. For comparison, the removal efficiency under the same condition of the as-obtained alumina microfibers transformed from $\mathrm{AACH}$ prepared with surfactant of (a) no surfactant, (b) PEG20000, and (c) PEG2000, respectively, was shown in Figure 6(B) and indicated that both of the samples (a) and (c) can remove about $100 \%$ of the Congo red after 30 mins, while (b) can remove $75 \%$ of that. From the results, it can be deduced that the adsorption abilities should be related to their specific surface area and the pore volume. The large surface area and pore volume combined with excellent thermal stability enhance the potential applications of these mesoporous alumina fibers in water treatment, as well as catalysis and catalysis supports. 


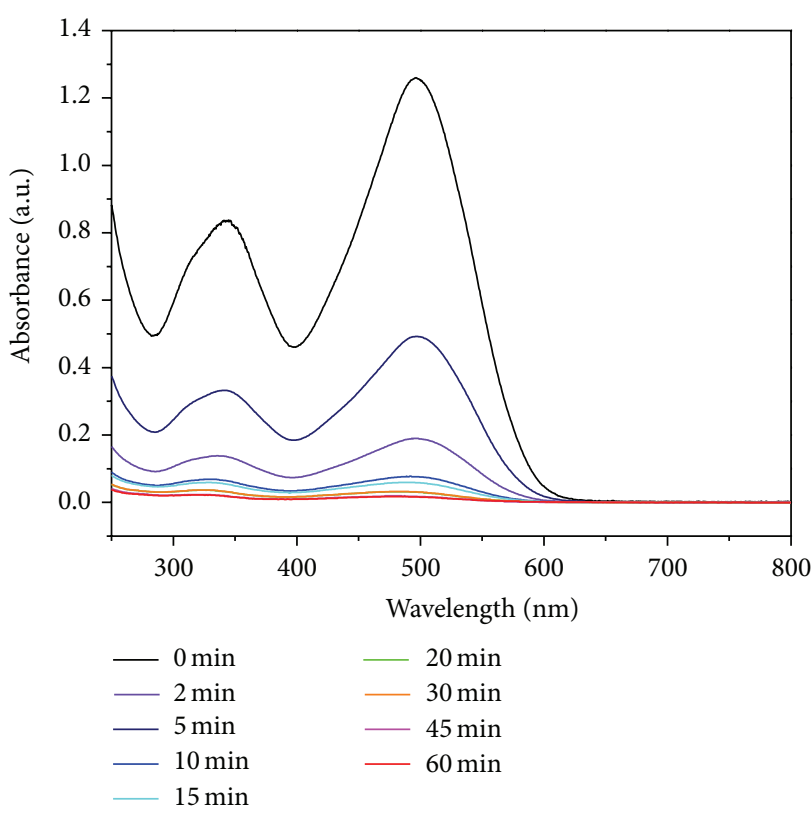

(A)

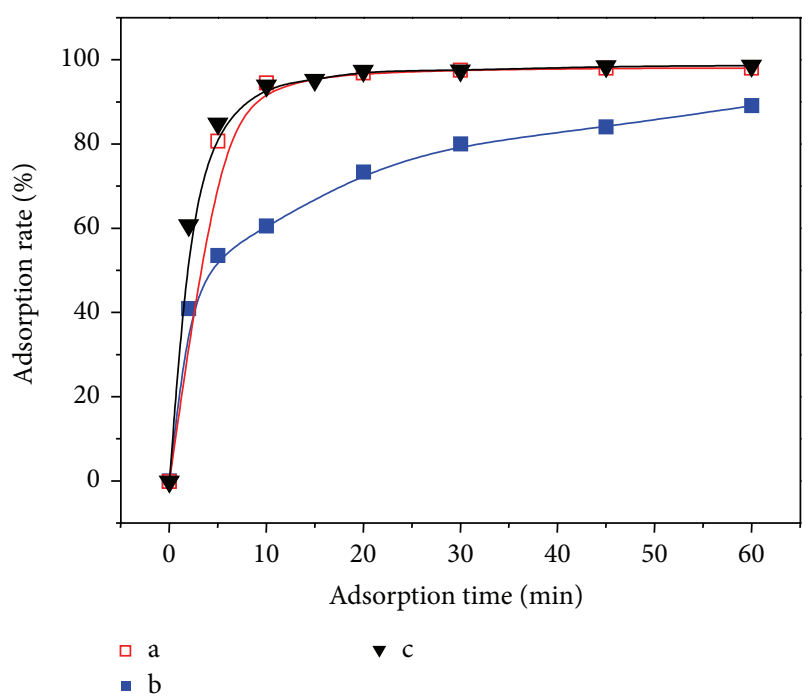

(B)

FIGURE 6: (A) Absorption spectrum of Congo red solution in the presence of $\gamma-\mathrm{Al}_{2} \mathrm{O}_{3}$ transformed from AACH prepared with surfactant of PEG2000. (B) Adsorption rates of the Congo red on $\gamma-\mathrm{Al}_{2} \mathrm{O}_{3}$ transformed from AACH prepared with surfactant of (a) no surfactant, (b) PEG20000, and (c) PEG2000, respectively.

\section{Conclusions}

In summary, $\gamma$-alumina microfibers with mesoporous of 3$25 \mathrm{~nm}$ were synthesized by a hydrothermal and the followed thermal decomposition route. AACH obtained by the hydrothermal method was used as the precursors and converted to $\mathrm{Al}_{2} \mathrm{O}_{3}$ after thermal-decomposition treatment without the morphology deformation. The formation of mesoporous structures is due to the release of $\mathrm{H}_{2} \mathrm{O}$ and decomposition of PEG and AACH precursors. And the release of $\mathrm{H}_{2} \mathrm{O}, \mathrm{NH}_{3}$, and $\mathrm{CO}_{2}$ from $\mathrm{AACH}$ when calcined has the most important influence to specific surface area and the pore volume. The $\gamma$-alumina microfibers exhibited excellent ability to remove organic pollutants from waste water because of their mesoporous structures. The $\gamma$-alumina converted from AACH synthesized without surfactant exhibited middle adsorption ability for Congo red between that synthesized with PEG20000 and PEG2000 which may provide a facile method to synthesize promising sorbent and catalyst.

\section{Conflict of Interests}

The authors declare that there is no conflict of interests regarding the publication of this paper.

\section{Authors' Contribution}

Adding Haibo Zeng to the authors list is because of his contribution to the revised paper.

\section{Acknowledgments}

This work is supported by the National Basic Research Program of China (Grant no. 2014CB931700), the Natural Science Foundation of Jiangsu Province (Grant no. BK2011709), the Undergraduate Student Research Training "key" Project of Nanjing University of Science and Technology, the National Natural Science Foundation of China (Grant no. 61222403), and the Natural Science Foundation of Hubei Province (Grant no. 2013CFC013).

\section{References}

[1] H. Liu, H. J. Sun, and J. Q. Li, "pH-dependent formation of AACH fibers with tunable diameters and their in situ transformation to alumina nanocrystals with mesoporous structure," Advanced Powder Technology, vol. 23, no. 2, pp. 164-169, 2012.

[2] J. Li, W. Li, X. Nai, S. Bian, X. Liu, and M. Wei, "Synthesis and formation of alumina whiskers from hydrothermal solution," Journal of Materials Science, vol. 45, no. 1, pp. 177-181, 2010.

[3] X. Y. Chen and S. W. Lee, "pH-Dependent formation of boehmite $(\gamma$-AlOOH) nanorods and nanoflakes," Chemical Physics Letters, vol. 438, no. 4-6, pp. 279-284, 2007.

[4] J. Zhang, S. Wei, J. Lin et al., "Template-free preparation of bunches of aligned boehmite nanowires," Journal of Physical Chemistry B, vol. 110, no. 43, pp. 21680-21683, 2006.

[5] H. Y. Zhu, X. P. Gao, D. Y. Song et al., "Growth of boehmite nanofibers by assembling nanoparticles with surfactant micelles," Journal of Physical Chemistry B, vol. 108, no. 14, pp. 4245-4247, 2004. 
[6] H. Hou, Y. Xie, Q. Yang, Q. Guo, and C. Tan, "Preparation and characterization of $\gamma$-AlOOH nanotubes and nanorods," Nanotechnology, vol. 16, no. 6, pp. 741-745, 2005.

[7] S. Cabrera, J. E. Haskouri, J. Alamo et al., "Surfactant-assisted synthesis of mesoporous alumina showing continuously adjustable pore sizes," Advanced Materials, vol. 11, no. 5, pp. 379381, 1999.

[8] Q. Huo, D. I. Margolese, U. Ciesla et al., "Generalized synthesis of periodic surfactant/inorganic composite materials," Nature, vol. 368, no. 6469, pp. 317-321, 1994.

[9] P. Bai, W. Xing, Z. Zhang, and Z. Yan, "Facile synthesis of thermally stable mesoporous crystalline alumina by using a novel cation-anion double hydrolysis method," Materials Letters, vol. 59, no. 24-25, pp. 3128-3131, 2005.

[10] Z. Zhang, R. W. Hicks, T. R. Pauly, and T. J. Pinnavaia, "Mesostructured forms of $\gamma-\mathrm{Al}_{2} \mathrm{O}_{3}$," Journal of the American Chemical Society, vol. 124, no. 8, pp. 1592-1593, 2002.

[11] F. Vaudry, S. Khodabandeh, and M. E. Davis, "Synthesis of pure alumina mesoporous materials," Chemistry of Materials, vol. 8, no. 7, pp. 1451-1464, 1996.

[12] B. Xu, T. Xiao, Z. Yan et al., "Synthesis of mesoporous alumina with highly thermal stability using glucose template in aqueous system," Microporous and Mesoporous Materials, vol. 91, no. 1-3, pp. 293-295, 2006.

[13] Z. Shan, J. C. Jansen, W. Zhou, and T. Maschmeyer, "A1-TUD1, stable mesoporous aluminas with high surface areas," Applied Catalysis A, vol. 254, no. 2, pp. 339-343, 2003.

[14] Z. Zhang, P. Bai, B. Xu, and Z. J. Yan, "Synthesis of mesoporous alumina TUD-1 with high thermostability," Journal of Porous Materials, vol. 13, no. 3-4, pp. 240-250, 2006.

[15] X. Liu, Y. Wei, D. Jin, and W. H. Shih, "Synthesis of mesoporous aluminum oxide with aluminum alkoxide and tartaric acid," Materials Letters, vol. 42, no. 3, pp. 143-149, 2000.

[16] Z. F. Zhu, H. J. Sun, H. Liu, and D. J. Yang, "PEG-directed hydrothermal synthesis of alumina nanorods with mesoporous structure via AACH nanorod precursors," Journal of Materials Science, vol. 45, no. 1, pp. 46-50, 2010.

[17] Z. S. Wu, Y. D. Shen, Y. Dong, and J. Q. Jiang, "Study on the morphology of $\alpha-\mathrm{Al}_{2} \mathrm{O}_{3}$ precursor prepared by precipitation method," Journal of Alloys and Compounds, vol. 467, no. 1-2, pp. 600-604, 2009.

[18] Z. Zhu, H. Liu, H. Sun, and D. Yang, "PEG-directed hydrothermal synthesis of multilayered alumina microfibers with mesoporous structures," Microporous and Mesoporous Materials, vol. 123, no. 1-3, pp. 39-44, 2009.

[19] L. S. Zhong, J. S. Hu, H. P. Liang et al., "Self-assembled 3D flowerlike iron oxide nanostructures and their application in water treatment," Advanced Materials, vol. 18, no. 18, pp. 24262431, 2006. 

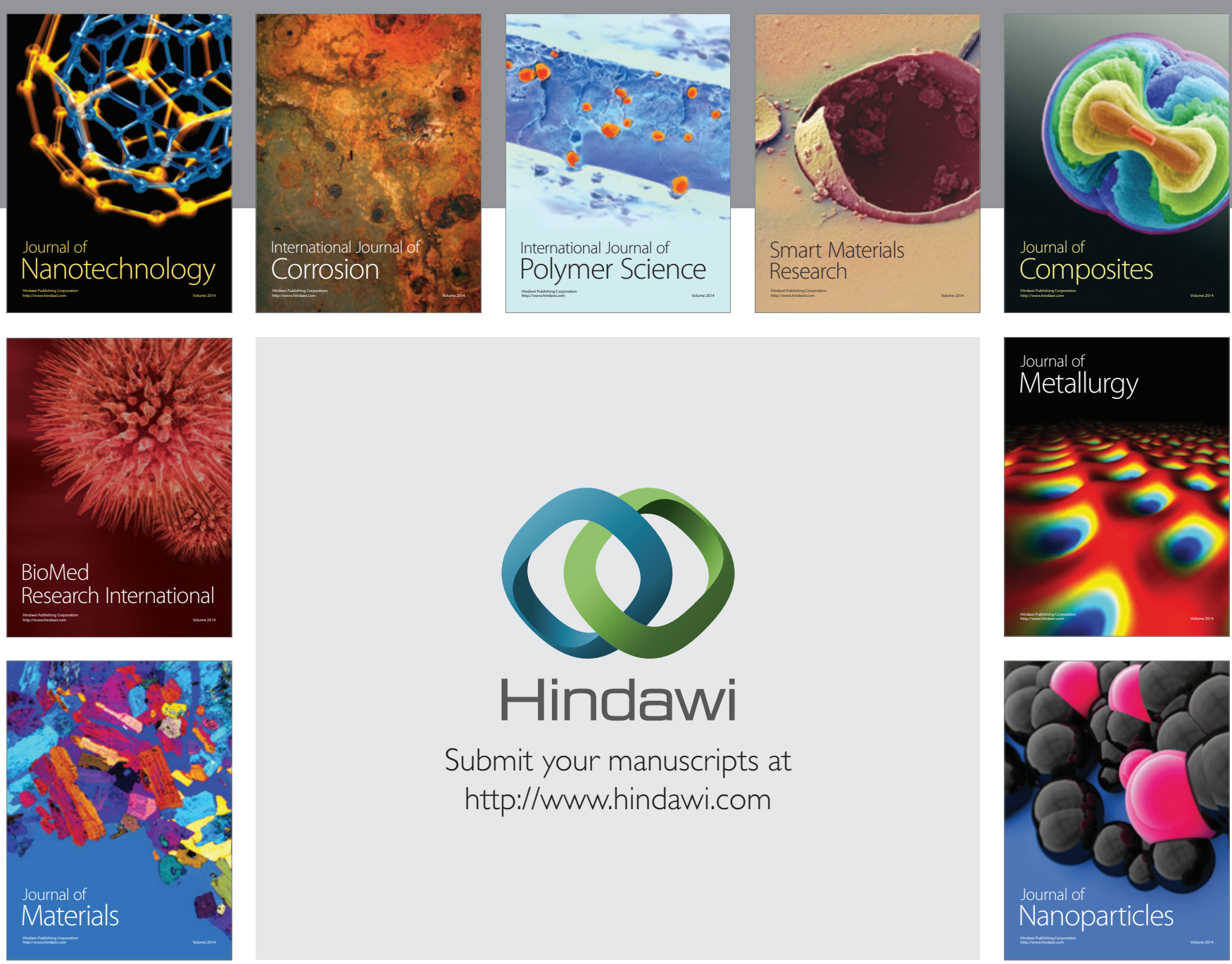

Submit your manuscripts at http://www.hindawi.com
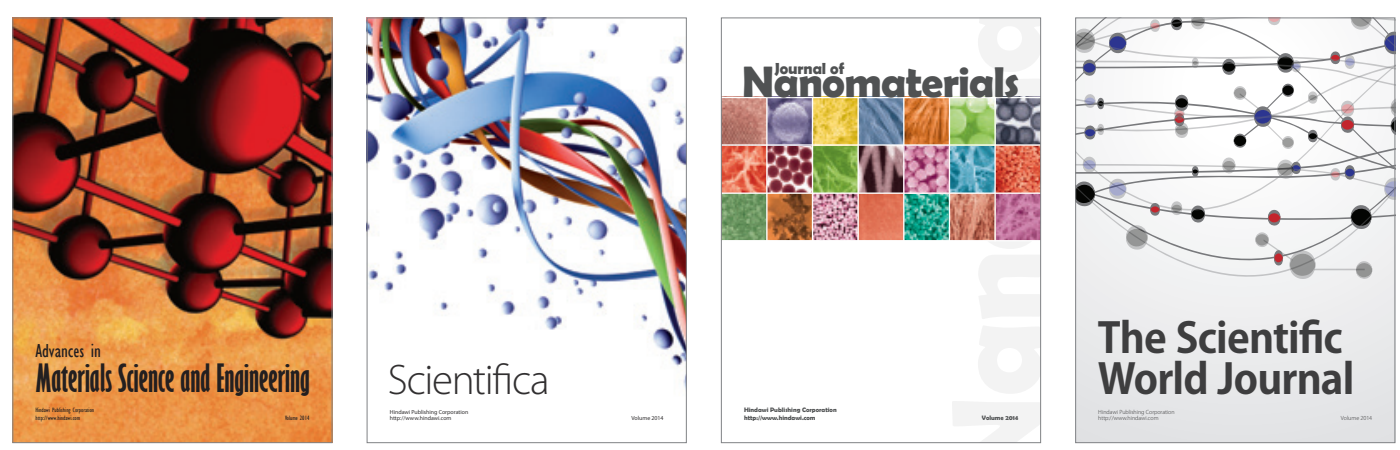

\section{The Scientific World Journal}
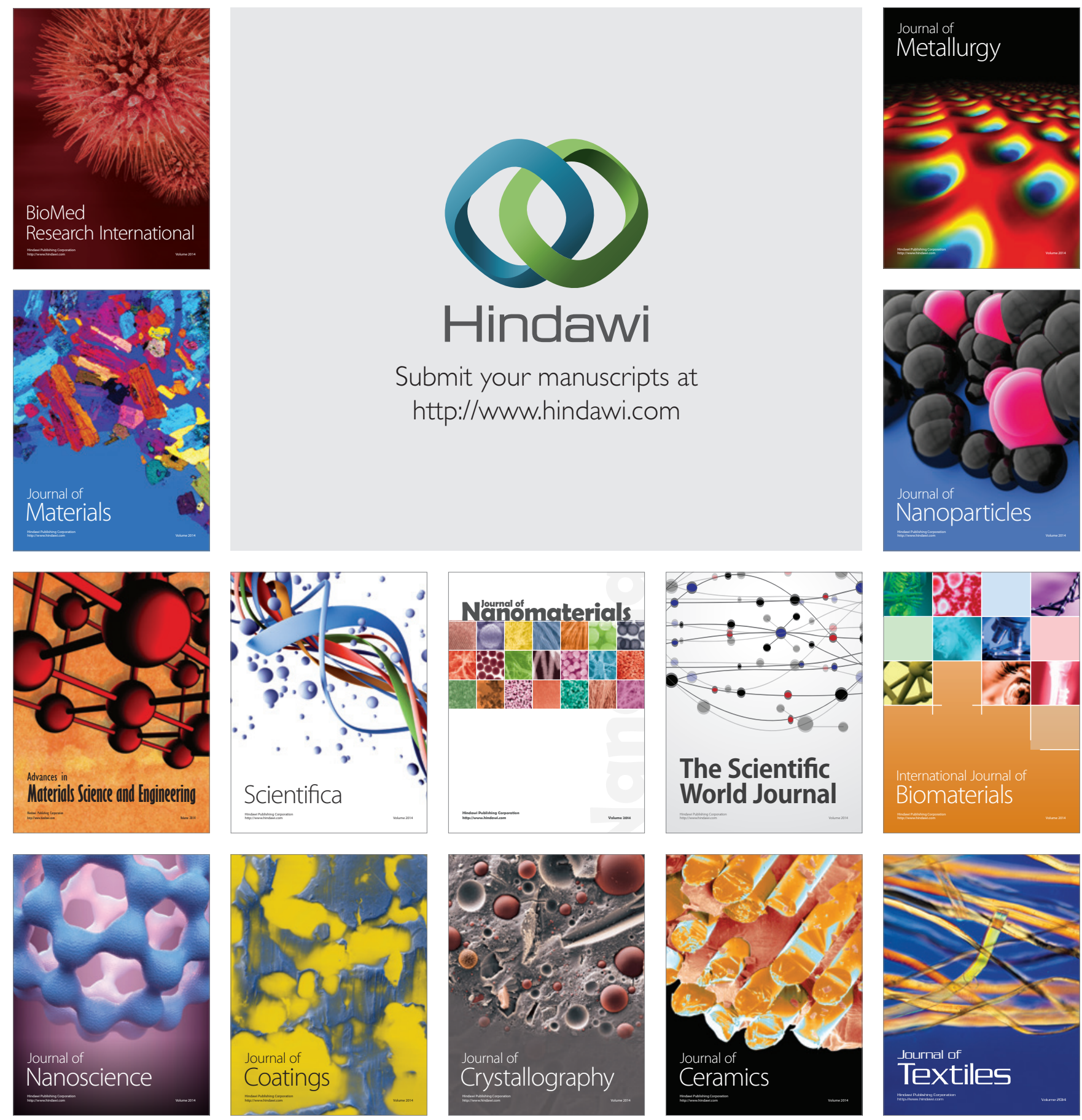